\title{
Rheological properties and curing features of natural rubber compositions filled with fluoromica ME 100
}

\author{
Luciana Honoratoํㅜ Marcos Lopes Dias ${ }^{1}$, Chiaki Azuma² and Regina Célia Reis Nunes ${ }^{1 *}$ \\ ${ }^{1}$ Instituto de Macromoléculas Professora Eloísa Mano - IMA, Universidade Federal do Rio de Janeiro - \\ UFRJ, Rio de Janeiro, RJ, Brazil \\ ${ }^{2}$ The Open University of Japan, Chiba, Japão \\ *rcnunes@ima.ufrj.br
}

\begin{abstract}
This work aims at studying not only the rheological behavior of natural rubber-based compositions by making use of different contents of fluoromica or ME 100 synthetic mica in a natural rubber (NR) matrix, but also the different filler-filler and matrix-filler interactions before and after curing. The ME 100 content in NR varied from 0 to 10 phr (parts per hundred parts of resin) and the results enabled to conclude on the influence of the mineral filler on the curing parameters, as well as on the limit amount of ME 100 for the best performance resulting from the best filler distribution/interaction in the polymer matrix. All data were compared with those of the unfilled composition. Based on complex viscosity, curing parameters, dynamic modulus and Payne effect tests it was concluded that the mica content limit for the best performance was $7 \mathrm{phr}$.
\end{abstract}

Keywords: rheology, natural rubber, synthetic mica, fluoromica.

\section{Introduction}

Natural rubber (NR) is one of the worldwide most widely consumed polymers in view of the combination of its unique properties, such as high tensile and tear strength besides excellent dynamic properties, which renders it a strategic and irreplaceable material for the manufacture of large-sized tires ${ }^{[1,2]}$.

In order that the elastomeric compositions find technological applications there is the need of a formulation including filler system, curing system, processing agents and protection agents such as antioxidants and antiozonants. Such constituents modify the composite viscosity with direct reflections on processing as well as on the articles' final properties. Being polymers, the behavior of elastomeric compositions is intermediary between viscous and elastic states, the knowledge of the viscoelastic profile, which can be studied by rheology, being extremely important for the processing prediction as well as for the final properties of the vulcanized elastomer. In the elastomer field, the rheology is mainly studied with the aid of the following equipment: Oscillating Disc Rheometer, Mooney Viscometer and Rubber Processing Analyzer ${ }^{[1-4]}$.

The relevant features exhibited by NR makes it the object of countless research, where the search for new methodologies of chemical modifications and the use of different kinds of fillers has aroused the interest in present research so as to widen its area of application ${ }^{[5-10]}$.

Besides carbon black and silica, which are long-established materials as reinforcement nanoparticles for a wide variety of rubbers, other functionalized or not nanofillers have been studied ${ }^{[6-9]}$. Among these fillers, synthetic micas which are light and have a similar structure to that of montmorillonite clay are being used as fillers for polymer compositions.
In a general way, synthetic micas are prepared from talc by introducing an alkaline metal into the interlamellar galleries. The advantage of using synthetic phyllosilicates as compared with natural mica is due to variables such as purity and composition, it admitting to be modified to suit the matrix to which it is to be incorporated ${ }^{[11-14]}$.

In this work synthetic ME 100 mica free of any surface treatment was used, at contents of from 0 to $10 \mathrm{phr}$ (parts per hundred parts of resin) in composition with natural rubber, an efficient curing system being added to the formulation ${ }^{[2,15,16]}$.

The rheology of all the compositions with NR was assessed based on the results provided by the RPA 2000 rubber processing analyzer, which enables to assess not only the curing parameters, but also the filler-filler and filler-polymer interactions by the Payne Effect before and after crosslink formation ${ }^{[8,9,17,18]}$.

\section{Materials and Methods}

\subsection{Preparation of the composites}

In this work natural rubber (NR) of Mooney viscosity $82 \mathrm{ML}(1+4)$ at $100{ }^{\circ} \mathrm{C}$ was used, and as filler, synthetic mica or Somasif ME 100 fluoromica, supplied by CO-OP Chemical Co., Ltd, Japan, with cationic exchange capacity (CEC) of $120 \mathrm{meq} / 100 \mathrm{~g}$.

The curing system used in this study was the efficient ${ }^{[2,15,16]}$ one, which has the following formulation in phr: NR 100; $\mathrm{ZnO} 3.5$; stearic acid 2.5; Irganox 1010 [Pentaerythritol tetrakis(3-(3,5-di-tert-butyl-4-hydroxyphenyl)propionate)] 2.0; and TMTD (Tetramethylthiuram disulfide) 3.0. An unfilled composition (NR/ME 100 0phr) was also obtained aiming at the comparison of results for formulations 
with 1, 2, 3, 5, 7 and $10 \mathrm{phr}$ of ME 100 mica. All chemicals were used as received.

The blends were performed in accordance with the ASTM D 3184 Method, in a Lab Tech Engineering Company LTDA LRMR-SC- $150 / 0$ roll mixer at $30^{\circ} \mathrm{C}$ and roll speed of $24: 40$.

\subsection{Rheological properties}

The properties of the NR compositions related to Complex Viscosity, Curing Rheometric Parameters, Payne Effect and further rheological characterizations were assessed with the aid of the RPA 2000 rubber processing analyzer ${ }^{[17,18]}$. This equipment is specifically designed for the measurement of properties in cured and uncured rubber compositions so as to comply with international standards such as the ASTM D 5289 and ASTM D 2084 Methods, which were used in this work. As for torque, the measurement tolerance is $0.5 \%$ of the working range and for the temperature accuracy is $\pm 0.3{ }^{\circ} \mathrm{C}$ of the test temperature.

\subsubsection{Curing rheometric parameters}

Curing rheometric parameters were assessed with the aid of the RPA instrument at a constant temperature of $150{ }^{\circ} \mathrm{C}$, with oscillating arch of $1^{\circ}$, frequency of $1 \mathrm{~Hz}$, for one hour, on compositions obtained in the rollmill using formulations with the efficient cure system specified in item 2.1. Maximum torque $\left(\mathrm{M}_{\mathrm{H}}\right)$, Minimum Torque $\left(\mathrm{M}_{\mathrm{L}}\right)$, Curing Time $\left(\mathrm{T}_{90}\right)$ Pre-Curing Time $\left(\mathrm{T}_{\mathrm{sl}}\right)$ and Curing Rate Index (CRI) were taken and/or calculated from the elastic torque plot (S') versus time supplied by the RPA equipment ${ }^{[19-22]}$.

\subsubsection{Complex viscosity}

Aiming at studying the effect of ME 100 on NR without the interference of the other additives of the formulation, the assessment of the complex viscosity was the test of choice. The filler-rubber blends were performed in a rolling mill, under the experimental conditions described in item 2.1, under a homogenization period of 5 minutes for each composition. Unfilled NR (PG) was submitted to the same experimental conditions.

By using the RPA equipment at $100^{\circ} \mathrm{C}$ and frequency of $0.5 \mathrm{~Hz}$ a plot of complex viscosity as a function of shear rate was obtained for deformations between $0.5^{\circ}$ and $80^{\circ}$. From this plot were extracted figures of complex viscosity for each composition at $0.5^{\circ}$ deformation.

\subsection{Payne effect}

The polymer-filler and filler-filler interactions were estimated based on the Payne Effect ${ }^{[23-29]}$.

The test was carried out in the RPA instrument by the analysis of the strain scanning applied to the compositions in the range between 0 and $100 \%$ and frequency of $1 \mathrm{~Hz}$ before and after cure at $60^{\circ} \mathrm{C}$. For the assessment of the post-cure Payne Effect, the compositions were previously submitted to $150^{\circ} \mathrm{C}$ in the equipment itself for the curing times $\left(\mathrm{T}_{90}\right)$ specified for each composition, as reported in the item Curing Rheometric Parameters.

By using RPA it was also possible to study the elastic modulus (G') as a function of frequency (from 0.1 to $10 \mathrm{~Hz}$ ) at $150{ }^{\circ} \mathrm{C}$ at the deformation of $0.5^{\circ}$.

\section{Results and Discussion}

\subsection{Complex viscosity}

The polymer-filler and/or filler-filler interactions influence the viscosity of mixtures and were analyzed before cure by comparing two parameters: one related to the complex viscosity $\left(\eta^{*}\right)$ for compositions with only $\mathrm{NR} /$ mica at $0.5^{\circ}$ deformation, and the other parameter related to the minimum torque, which is the viscosity of the compositions with the complete additives. The results are displayed on Figure 1 and are compared with those of the unfilled composition.

Data of Figure 1 show that above $5 \mathrm{phr}$ mica has a significant influence on the complex viscosity of the compositions, corroborating the results for minimum torque $\left(\mathrm{M}_{\mathrm{L}}\right)^{[18-22]}$. According to Chen et al. ${ }^{[20]}$, surface adhesion between the filler and the matrix hinders the flow of elastomeric compositions as a result of the partial formation of phase interactions ${ }^{[19,20]}$. In this way, data of Figure 1 allow to estimate the NR-ME 100 mica interactions. It can be observed that for both properties studied, complex viscosity and minimum torque, there is increasing growth as a function of the filler content, potentialized for the $7 \mathrm{phr}$ composition, meaning higher rubber-filler interaction. Beyond this formulation, that is, for $10 \mathrm{phr}$ mica the viscosity increase is lower, $7 \mathrm{phr}$ being possibly an indication of the filler limit content in the composition meaning better dispersion and distribution within the elastomeric matrix ${ }^{[23-27]}$.

\subsection{Cure rheometric parameters}

The results of the cure rheometric parameters for the NR/ME 100 and pure gum are listed in Table 1. It can be observed that the presence of the filler does not interfere in the pre-curing time $\left(\mathrm{T}_{\mathrm{s} 1}\right)$ (or safety period of the curing process), but causes a slight increase in the curing period $\left(\mathrm{T}_{90}\right)$ and as a consequence, a reduction in the curing rate index (CRI) relative to the pure gum, meaning an influence on the process of crosslink formation. The less favorable result is for the composition of the highest fluoromica content, 10 phr.

Assuming that the difference between torques $\left(\Delta \mathrm{M}=\mathrm{M}_{\mathrm{H}}-\mathrm{M}_{\mathrm{L}}\right)$ is related to crosslink density ${ }^{[22]}$, the fluoromica incorporation exerts positive influence on the

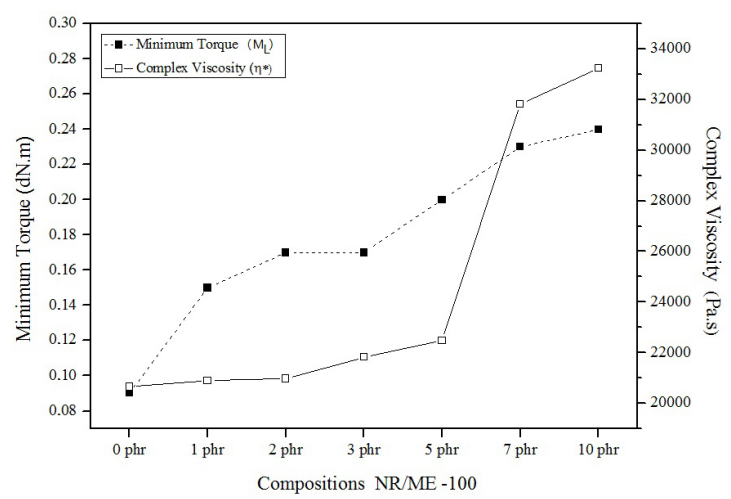

Figure 1. Minimum Torque and Complex Viscosity as a function of the ME 100 mica content in uncured NR compositions. 
Table 1. Cure rheometric parameters of the NR/ME 100compositions.

\begin{tabular}{|c|c|c|c|c|c|c|}
\hline $\begin{array}{c}\text { NR/ME } 100 \\
\text { (phr) }\end{array}$ & $\begin{array}{c}M_{L}^{\text {(a) }} \\
\text { (dN.m) }\end{array}$ & $\begin{array}{c}M_{H^{(a)}} \\
\text { (dN.m) }\end{array}$ & $\begin{array}{c}M_{H}-M_{L}{ }^{\text {(a) }} \\
\text { (dN.m) }\end{array}$ & $\begin{array}{c}T_{\mathrm{s} 1} \\
\text { (min.) }\end{array}$ & $\begin{array}{c}T_{90} \\
\text { (min.) }\end{array}$ & $\begin{array}{c}\text { CRI } \\
\left(\mathrm{min}^{-1}\right) \\
\end{array}$ \\
\hline $100 / 00$ & 0.09 & 7.34 & 7.25 & 2.48 & 9.55 & 14.14 \\
\hline $100 / 01$ & 0.15 & 8.11 & 7.96 & 2.23 & 10.03 & 12.82 \\
\hline $100 / 02$ & 0.17 & 8.15 & 7.98 & 2.36 & 10.45 & 12.36 \\
\hline $100 / 03$ & 0.17 & 8.00 & 7.83 & 2.34 & 10.36 & 12.46 \\
\hline $100 / 05$ & 0.20 & 8.30 & 8.10 & 2.53 & 10.40 & 12.70 \\
\hline $100 / 07$ & 0.23 & 8.57 & 8.34 & 2.57 & 10.58 & 12.48 \\
\hline $100 / 10$ & 0.24 & 7.39 & 7.15 & 2.50 & 12.23 & 10.27 \\
\hline
\end{tabular}

(a) The torque $\left(\mathrm{M}_{\mathrm{L}}\right.$ or $\left.\mathrm{M}_{\mathrm{H}}\right)$ measurement tolerance is of $0.5 \%$ of the working range.

7 phr composition, corroborating the results shown in Figure 1. The maximum torque $\left(\mathrm{M}_{\mathrm{H}}\right)$, which is related to molecular rigidity, is the lowest for the $10 \mathrm{phr}$ formulation among the filled compositions, this being an indication of the low rubber-filler interaction.

Based on the obtained results the cure rheometric parameters point out to the $7 \mathrm{phr}$ ME 100 composition as the most favorable, predicting the best possible interaction/distribution for this filler content with the elastomeric matrix ${ }^{[3,4,6-9,22,26,27]}$.

\subsection{Payne effect}

The occurrence of a tridimensional network formed by the filler is important since it modifies the physical properties of the elastomeric compositions, significantly affecting the dynamic viscoelastic properties of the rubber articles. The filler-filler interaction is a ruling factor for hysteresis rise, and is directly related to the breaking and reconstitution of these structures of secondary aggregates in filled rubber compounds when submitted to strains. Such interactions have been studied by Payne (Payne Effect) through the influence of strain amplitude on elastic modulus. The Payne Effect can be calculated by the difference between the elastic moduli before and after cure, with a specific value of strain $\left(\Delta \mathrm{G}^{\prime}=\mathrm{G}^{\prime}{ }_{0}-\mathrm{G}_{\infty}{ }_{\infty}\right)$ while temperature and frequency are kept constant ${ }^{[23-29]}$.

In the present study the Payne Effect (filler-filler interaction) was calculated by the difference between the elastic modulus at $14 \%$ and at $100 \%$ strain $\left[\Delta \mathrm{G}^{\prime}=\left(\mathrm{G}^{\prime}{ }_{14 \%}-\mathrm{G}^{\prime}{ }_{100 \%}\right)\right]$ in cured and uncured compositions, at $1 \mathrm{~Hz}$ and $60{ }^{\circ} \mathrm{C}$, the results obtained being displayed in Figures $2 \mathrm{~A}$ and $2 \mathrm{~B}$ respectively.

For the studied strain range the unfilled composition (NR/ME 100 0phr) as well as the filled ones exhibited non linear behavior before as well as after cure. By increasing filler content the distances among aggregates become shorter and therefore there is increased probability of occurrence of a tridimensional network formed by the augmented filler ${ }^{[23,25-28]}$. Data of Figures 2A and 2B show reduced elastic modulus value with the increase in strain amplitude for all of the mica-reinforced compounds, this phenomenon being explained by the "Payne Effect"[23,27].

In this way, the compositions with fluoromica ME 100, as compared with the pure gum composition had higher G' values relative to the applied strain, absorbing more energy as a result of their higher rigidity and thus corroborating the results for elastic torque in the curing test.
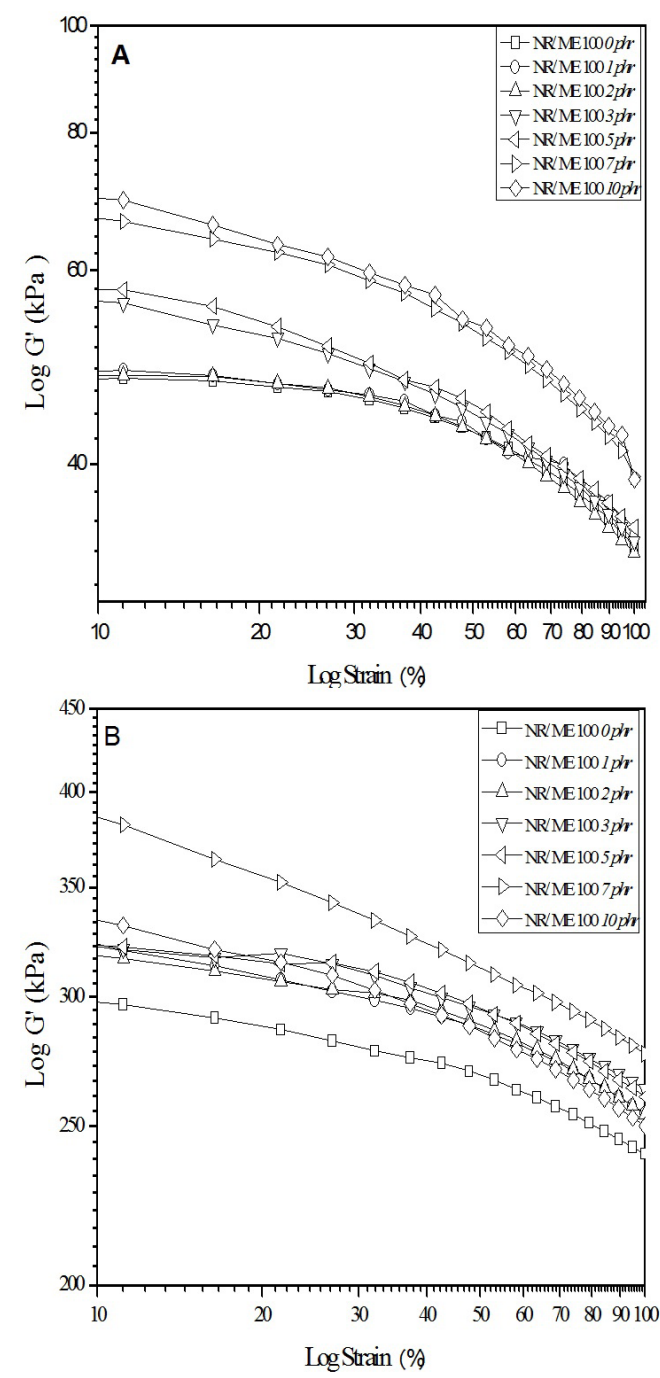

Figure 2. Payne Effect: Elastic Modulus for NR/Pure Gum and NR/ME 100 compositions as a function of strain: (A) before cure (B) after cure.

After cure, the curves are shifted towards higher modulus values as a result of filler increase, exception made to the formulation with $10 \mathrm{phr}$ mica where the modulus value is lower than that for the $7 \mathrm{phr}$ composition. This behavior points out to $7 \mathrm{phr}$ filler as limit value for the developed formulation. 
The accentuated reduction in the G'value resulting from the strain rate is due to the breaking of the filler-filler interaction and consequently the dismantlement of the polymer-filler tridimensional network. The increased G' value observed in the low strain region is in agreement with the Payne Effect that is, an indication of the rubber-filler interaction ${ }^{[23,27]}$. In Figure 2B it can be observed that the highest value for $\mathrm{G}^{\prime}$ is for the $7 \mathrm{phr}$ filler composition.

Figure 3 shows the data for the Payne Effect for cured and uncured compositions calculated from the difference between moduli at $14 \%$ and $100 \%$ strain $\left[\Delta G^{\prime}=\left(G^{\prime}{ }_{14 \%}-G^{\prime}{ }_{100 \%}\right)\right]$. There is an increase in $\Delta \mathrm{G}^{\prime}$ (Payne Effect) after cure due to

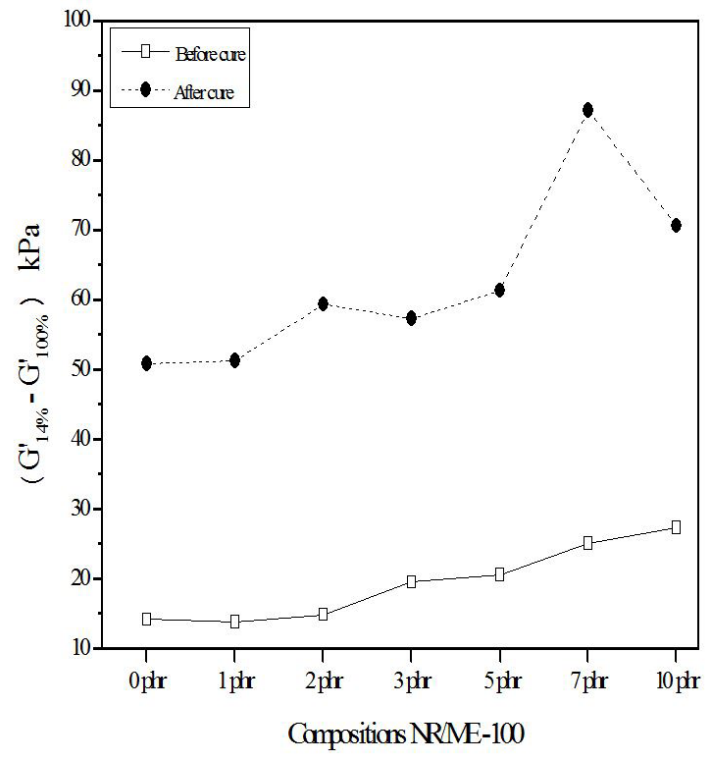

Figure 3. Payne Effect $\left[\Delta \mathrm{G}^{\prime}=\left(\mathrm{G}^{\prime}{ }_{14 \%}-\mathrm{G}^{\prime}{ }_{100 \%}\right)\right]$ for the NR/Pure Gum and NR/ME 100 compositions before and after cure.

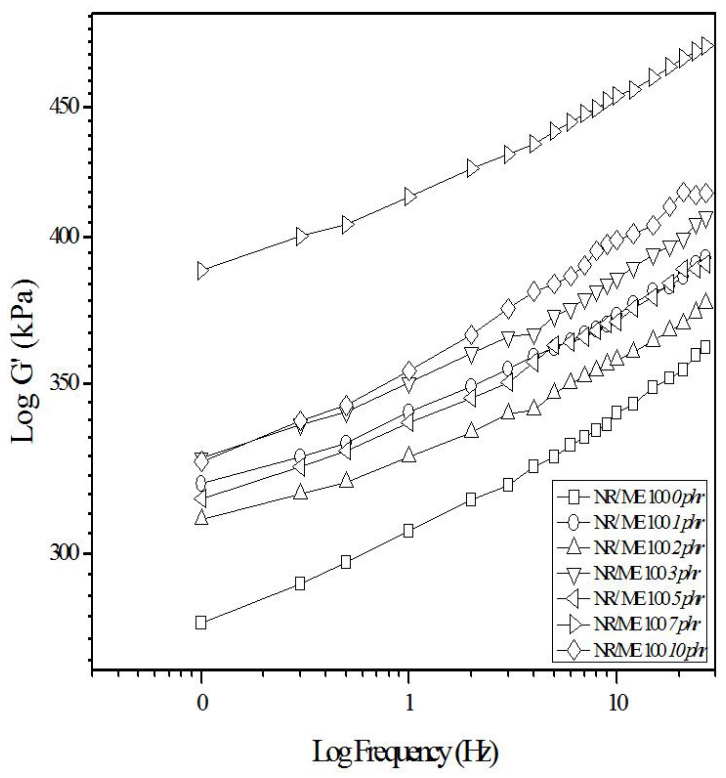

Figure 4. Elastic Modulus ( $\mathrm{G}^{\prime}$ ) as a function of frequency for the NR/Pure Gum and NR/ME 100 compositions. the probable re-aggregation of the filler by the low viscosity of the polymer matrix during crosslinks formation at high temperatures. The Payne Effect will be higher the greater is the value of $\Delta \mathrm{G}^{\prime}$, meaning a higher break of filler-filler interactions, and consequently, higher amount of filler agglomerates in the elastomer matrix. The highest value was obtained for the $7 \mathrm{phr}$ ME 100 fluoromica composition after cure ${ }^{[23,27]}$.

The elastic modulus for the NR/Pure Gum and NR/Mica compositions was also studied as a function of frequency (Figure 4). As relates pure gum the graphic results show that during all the frequency scanning modulus G' was higher for all of the mica compositions, this being due to interactions, which are quantified by the Payne Effect. G'values at low frequencies are lower than those for high frequency as a consequence of the molecular movement differentiated relaxation times, which is hindered by filler addition. Whenever a polymer is strained at higher frequencies the chains are not allowed sufficient time to relax, and the modulus increases ${ }^{[29]}$. The $7 \mathrm{phr}$ mica composition has a significant higher modulus throughout the whole range of frequency studied due to the better interaction with the NR matrix, corroborating the remaining analyzed results.

\section{Conclusions}

Non-surface treated fluoromica ME 100 added to natural rubber has modified the curing features of the compositions and the rheological properties for the studied contents.

The cure results led to the conclusion that fluoromica ME 100 interfered in crosslinks formation by the values of the difference between maximum torque and minimum torque, by the increased curing time and by the reduction in the cure rate coefficient.

Based on the Payne Effect theory it was possible to measure the filler-matrix and filler-filler interactions for the NR composites with fluoromica ME 100 before and after cure.

Results for complex viscosity corroborated the remaining tests and indicated $7 \mathrm{phr}$ as the limit ME100 amount for the best performance in natural rubber under the processing conditions reported in this work, resulting from the better filler distribution/interaction in the polymer matrix.

\section{Acknowledgements}

The authors are indebted to CNPq, CAPES and FAPERJ for financial support and to the Grupo Teadit for the donation of natural rubber, additives and further materials employed during the course of this research.

\section{References}

1. Kohjiya, S. (2015). Natural rubber: from the odyssey of the hevea tree to the age of transportation. Shawabury: Smithers Rapra.

2. Roberts, A. D. (1988). Natural rubber science and technology. Oxford: Oxford University Press.

3. Wang, Z., Lwo, W., Fang, L., Liao, S., Li, L., Lin, H., Li, S., \& He, C. (2014). Rheological behavior of raw natural 
rubber coagulated by microorganisms. Polímeros: Ciência e Tecnologia, 24(2), 143-148.

4. Martins, A. F., Visconte, L. L. Y., \& Nunes, R. C. R. (2002). Propriedades reológicas e dinâmicas de composições nãovulcanizadas de borracha natural com celulose regenerada. Polímeros: Ciência e Tecnologia, 12(4), 295-300.

5. Kohjiya, S., \& Ikeda, Y. (2014). Chemistry, manufacture and applications of natural rubber. Oxford: Woodhead Publishing.

6. Nunes, R. C. R. (2014). Natural rubber (NR) composites using cellulosic fiber reinforcements. In S. Kohjiya \& Y. Ikeda (Eds.), Chemistry, manufacture and applications of natural rubber (pp. 284-302). Oxford: Woodhead Publishing. http://dx.doi. org/10.1533/9780857096913.2.284

7. Galimberti, M., Cipolletti, V., Musto, S., Cioppa, S., Peli, G., Mauro, M., Gaetano, G., Agnelli, S., Theonis, R., \& Kumar, V. (2014). Recent advancements in rubber nanocomposites. Rubber Chemistry and Technology, 87(3), 417-442. http:// dx.doi.org/10.5254/rct.14.86919.

8. Bhattacharya, M., \& Bhowmick, A. K. (2010). Correlation of vulcanization and viscoelastic properties of nanocomposites based on natural rubber and different nanofillers, with molecular and supramolecular structure. Rubber Chemistry and Technology, 83(1), 16-34. http://dx.doi.org/10.5254/1.3548263.

9. Mariano, R. M., Nunes, R. C. R., Visconte, L. L. Y., \& Altstaedt, V. (2013). Efeito da hibridização de montmorilonita e celulose II sobre as propriedades mecânicas de nanocompósitos de borracha natural. Polímeros: Ciência e Tecnologia, 23(1), 123-127.

10. Escócio, V. A., Martins, A. F., Visconte, L. L. Y., Nunes, R. C. R., \& Costa, D. M. R. (2003). Influência da mica nas propriedades mecânicas e dinâmico-mecânicas de composições de borracha natural. Polímeros: Ciência e Tecnologia, 13(2), 130-134.

11. Souza, D. H. S., Dahmouche, S., Andrade, C. T., \& Dias, M. L. (2011). Structure, morphology and thermal stability of synthetic fluorine mica and its organic derivatives. Applied Clay Science, 54(3-4), 226-234. http://dx.doi.org/10.1016/j. clay.2011.09.006.

12. Tateyama, H., Tsunematsu, K., Kimura, K., Hirosue, H., Jinnai, K., \& Furusawa, T. (1993). Method for producing fluorine mica. US Patent 5204078.

13. Gelfer, M. Y., Burger, C., Nawani, P., Hsiao, B. S., Chu, B., Si, M., Rafailovich, M., Panek, G., Jeschke, G., Fadeev, A. Y., \& Gilman, J. W. (2007). Lamellar nanostructure in Somasif-based organoclays. Clays and Clay Minerals, 55(2), 140-150. http:// dx.doi.org/10.1346/CCMN.2007.0550203.

14. He, H., Duchet, J., Galy, J., \& Gérard, J. F. (2005). Grafting of swelling clay materials with 3-aminopropyltriethoxysilane. Journal of Colloid and Interface Science, 288(1), 171-176. http://dx.doi.org/10.1016/j.jcis.2005.02.092. PMid:15927576.

15. Morrison, N. J., \& Porter, M. (1984). Temperature effects on the stability of intermediates and crosslinks in sulfur vulcanization. Rubber Chemistry and Technology, 57(1), 63-85. http://dx.doi. org/10.5254/1.3536002.

16. Cunnen, J. I., \& Russell, R. M. (1970). Occurrence and prevention of changes in the chemical structure of natural rubber tire tread vulcanizates during service. Rubber Chemistry and Technology, 43(5), 1215-1224. http://dx.doi.org/10.5254/1.3547319.

17. Dick, J. S., Harmon, C., \& Vare, A. (1999). Quality assurance of natural rubber using the rubber process analyzer. Polymer
Testing, 18(5), 327-362. http://dx.doi.org/10.1016/S01429418(98)00026-9.

18. Leblanc, J. L. (2002). Rubber-filler interactions and rheological properties in filled compounds. Progress in Polymer Science, 27(4), 627-687. http://dx.doi.org/10.1016/S0079-6700(01)000405 .

19. Yahaya, L. E., Adebowale, K. O., \& Olu-Owolabi, B. I. (2014). Cure characteristics and rheological properties of modified kaolin-natural rubber composites. American Chemical Science Journal, 4(4), 472-480. http://dx.doi.org/10.9734/ ACSJ/2014/6575.

20. Chen, Y., Zhang, C., Wang, Y., Cheng, S., \& Chen, P. (2003). Study of self-crosslinking acrylate latex containing fluorine. Journal of Applied Polymer Science, 90(13), 3609-3616. http:// dx.doi.org/10.1002/app.13087.

21. Escócio, V. A. (2006). Hibridos de borracha natural com mica (Master's dissertation). Instituto de Macromoléculas Professora Eloisa Mano, Universidade Federal do Rio de Janeiro, Rio de Janeiro.

22. López-Manchado, M. A., Arroyo, M. A., Herrero, M. B., \& Biagiotti, J. (2003). Vulcanization kinetics of natural rubberorganoclay nanocomposites. Journal of Applied Polymer Science, 89(1), 1-15. http://dx.doi.org/10.1002/app.12082.

23. Payne, A. R. (1962). The dynamic properties of carbon black loaded natural rubber vulcanizates. Part I. Journal of Applied Polymer Science, 6(19), 57-63. http://dx.doi.org/10.1002/ app.1962.070061906.

24. Bezerra, F. O., Nunes, R. C. R., \& Ito, E. N. (2013). Efeito Payne em nanocompósitos de NBR com montmorilonita organofílica. Polímeros: Ciência e Tecnologia, 23(2), 223-228.

25. Léopoldès, J., Barrès, C., Leblanc, J. L., \& Georget, P. (2004). Influence of filler-rubber interactions on the viscoelastic properties of carbon-black-filled rubber compounds. Journal of Applied Polymer Science, 91(1), 577-588. http://dx.doi. org/10.1002/app.13155.

26. Wu, Y. P., Wang, Y. Q., Zhang, H. F., Wang, Y. Z., Yu, D. S., Zhang, L. Q., \& Yang, J. (2005). Rubber-pristine clay nanocomposites prepared by co-coagulating rubber latex and clay aqueous suspension. Composites Science and Technology, 65(7-8), 1195-1202. http://dx.doi.org/10.1016/j. compscitech.2004.11.016.

27. Fröhlich, J., Niedermeier, W., \& Luginsland, H. D. (2005) The effect of filler-filler and filler-elastomer interaction on rubber reinforcement. Composites. Part A, Applied Science and Manufacturing, 36(4), 449-460. http://dx.doi.org/10.1016/j. compositesa.2004.10.004.

28. Yurekli, K., Krishnamoorti, R., Tse, M. F., McElrath, K. O., Tsou, A. H., \& Wang, H. C. (2001). Strucuture and dynamics of carbon black-filled elastomers. Journal of Polymer Science. Part B, Polymer Physics, 39(2), 256-275. http:// dx.doi.org/10.1002/1099-0488(20010115)39:2<256::AIDPOLB80>3.0.CO;2-Z.

29. Barick, A. K., \& Tripathy, D. K. (2011). Effect of organically modified layered silicate nanoclay on the dynamic viscoelastic properties of thermoplastic polyurethane nanocomposites. Applied Clay Science, 52(3), 312-321. http://dx.doi.org/10.1016/j. clay.2011.03.010.

Received: Sept. 03, 2015

Revised: Feb. 04, 2016

Accepted: Feb. 24, 2016 